\title{
Declining mortality in the immature: medical or biological effect?
}

\author{
R SUNDERLAND ${ }^{1}$ AND A A GREENFIELD ${ }^{2}$ \\ From the Children's Hospital, ${ }^{1}$ Birmingham 16, and Department of Medical Statistics. ${ }^{2}$ Institute of Clinical \\ Science, Belfast, UK
}

SUMMARY A steady and significant decline in the proportions of liveborn infants who died in the first week from problems associated with immaturity occurred among Sheffield babies born between 1947 and 1979. The decline occurred in all three maternity units, regardless of the availability of neonatal care facilities. The rate of decline in the best equipped and best staffed hospital, however, was significantly greater during the 1970 s than would have been predicted from the trend in earlier years and in contrast to the other hospitals. This greater decline shows a closer temporal association with a reorganisation of labour wards and nurseries than with the introduction of advanced equipment but also correlates with an increasing abortion rate among women who would be expected to have premature deliveries. Factors responsible for the secular decline have? not been identified, but it is postulated that Sheffield's mothers are bearing healthier children as a result of improvements in maternal health which are themselves a consequence of changes during girlhood.

Infant mortality rates in the United Kingdom began to decline in 1902, the year of the Midwives' Act. Although these events have been causally associated, ${ }^{1}$ the decline was almost entirely due to the gradual disappearance of fatal infectious diseases in the postneonatal period (fig 1). Neonatal mortality was a relatively minor problem until the latter half of this century, and the lack of facilities and staff for neonatal intensive care units (NICU) has only recently received national attention. ${ }^{2}$

Attempts have been made to assess the effectiveness of advances in neonatal care but long term studies have been hampered by the lack of reliable data on the pathology of immature deaths. Most published studies have therefore been either of short time spans or have used relatively crude data. In particular, birthweight standardised records have become accepted as a suitable alternative to necropsy verified evidence of immaturity. Low birthweight infants, however, include an indeterminable and variable proportion of malformed infants who would be unlikely to be saved by recent advances in neonatal intensive care.

Large scale studies of early neonatal mortality are additionally hampered by invalid death certification, errors in the lay coding of death certificates, and changes in the classification of the causes of death. ${ }^{3}$

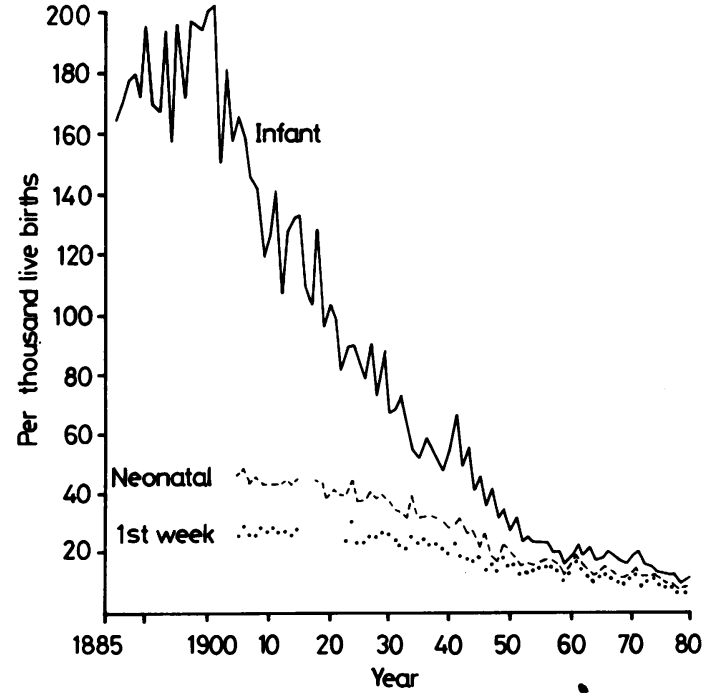

Fig 1 Sheffield infant, neonatal, and first week mortality rates, $1885-1979$. 
These large data sets are often pooled centrally and analysed by non-clinicians who have no control over the quality of information forwarded to them.4

In the present study we have therefore examined all original records in a single stable community served by several maternity hospitals with differing facilities for neonatal care which did not transfer prematurely born infants for intensive care so that secular trends and the benefits of specific hospital care could be analysed.

\section{Materials and methods}

Sheffield was chosen for study as it is a stable community with excellent obstetric, paediatric, and pathology services and there has been little migration in the past century. ${ }^{5}$

Every death certificate and necropsy report issued in Sheffield between 1947 and 1979 was examined by RS and details abstracted of children with a stated age of less than 7 completed days. Details of Sheffield children who died outside the city were obtained from the Sheffield Health Authority (Information Services) which also supplied details of live births by place of confinement. Children were included in the study if their given address was in the official Index of Sheffield Streets current at the time of death.

Six pathologists in the city were involved in paediatric work during the period studied, but almost all of the discovered neonatal necropsies were done by one of two pathologists. Where necessary the certified cause of death was modified and, without knowledge of the year of death, all deaths were then coded into a classification based on the ninth revision of the International Classification of Diseases (ICD-9). The deaths were grouped into five categories: (a) immaturity (prematurity, extreme prematurity, immaturity, respiratory distress syndrome, hyaline membrane disease, or primary atelectasis in the absence of any other pathology); (b) obstetric (maternal diseases, birth trauma, isoimmunisation, and placental complications); (c) malformation (all major congenital anomalies regardless of other pathology); (d) infection; and (e) other.

Sheffield had three large maternity units throughout the period studied (hospitals E, G, and H). Hospital $E$ was upgraded in the late 1960 s, thereafter taking increasing numbers of women who would previously have been delivered at home. This hospital primarily serves families with non-manual occupations. It shares paediatric staff with hospital G, some five miles away. Hospital $G$ serves most of the economically deprived, the latest immigrant communities, and a large proportion of the illegitimate births. "Unbooked" babies (see below) born prematurely at home were all taken here until the end of the 1960s when hospital $H$ began to take some. There was a central special care baby unit (SCBU) at hospital $G$ in the early 1960 s, but paediatric staff also covered general paediatric wards, outpatients department, and casualty as well as the neonatal service. From 1948, staff from the Children's Hospital attended hospital $\mathrm{H}$ and full time neonatal staff were appointed in the mid-1960s. Until the early 1970s, however, deliveries here were in two separate and independent sites and each postnatal ward had its own nursery for sick or small babies. Obstetric facilities at the three hospitals have been good throughout: hospital $\mathrm{H}$ has more obstetric staff but receives several high risk pregnancies from outlying areas (up to $20 \%$ of total deliveries) which are not considered here.

A maternity bed is booked through the antenatal clinic on a first come, first served basis. Sheffield women, as a broad generalisation, attend the hospital nearest home for confinement, although there is an apparent preference for delivery in hospital $\mathrm{H}$ as the obstetric and neonatal facilities there are perceived as being better. In accordance with the inverse care law, the beds in this hospital are often fully booked before many of the high risk mothers have attended an antenatal clinic. The effects of such social factors on biasing the distribution of birthweight, immaturity, and early mortality are well known. ${ }^{6}$

\section{Results}

Table 1 shows the quinquennial numbers and rates of Sheffield live births and first week deaths by cause. Table 2 shows the quinquennial numbers of live births and immaturity deaths by place of birth, and fig 2 shows the rate of first week deaths from immaturity per thousand live births for each hospital as a three year moving mean (unweighted). Births and deaths at home or in private maternity homes have been omitted from fig 2 for clarity. Table 3 gives the stillbirth, first day mortality, and birthweight specific neonatal mortality rates for the city and for hospital G (1953-79 only). The birthweight specific mortality rates include indeterminate numbers of lethal malformations. We could not trace any other consistent long term record of high risk Sheffield pregnancies by maternity hospital, but data from the Trent Regional Health Authority Hospital Activities Analysis for the period 1977-9, ranked by maternal age and birthweight, shows that most high risk pregnancies are delivered at hospital $G$ and fewest at hospital $E$, which may explain the continuing differences in immaturity mortality in these hospitals (fig 2).

Significant declines with time in the city's immaturity and obstetric mortality rates were shown by simple linear regression $(p<0 \cdot 01)$. The death rate due to 


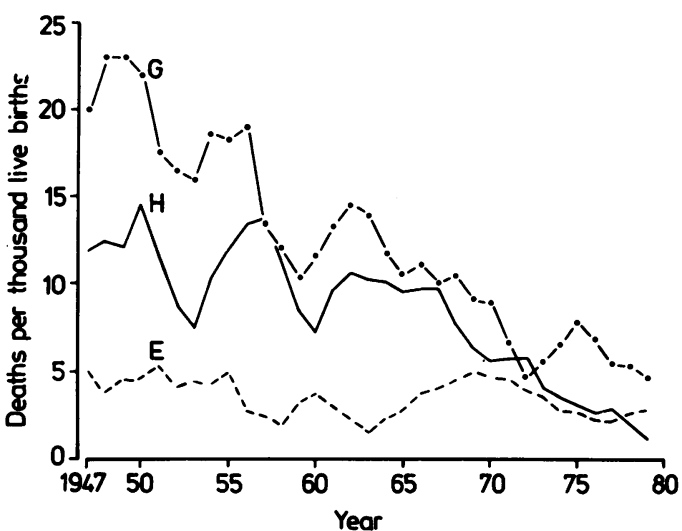

Fig 2 Rate of first week deaths from immaturity per thousand live births by maternity hospital, Sheffield 1947-79. malformations, however, increased $(p<0 \cdot 05)$, probably as a consequence of local changes in the management of neural tube defects. ${ }^{7}$

No significant change in variance of the proportions of infants dying from immaturity at each hospital was found between a single line fitted over the whole time span and two separate lines, linear or exponential, over the first 23 years and the last 10 (this division is because of the suggestion that available technology was inadequate before the 1970s). ${ }^{8-10}$ A significant $F$ value at $p<0.05$ is 1.84 . F values for each hospital were : E 0.966, G 0.967, H 1.085 (linear model), and E 1.00, G 0.972, H 1.299 (exponential model).

At hospital $\mathrm{H}$ alone, however, there was a significant change in the rate of decline of the proportions of infants dying from immaturity

Table 1 Sheffield live births and first week deaths, 1947-79. (Rates per 1000 livebirths)

\begin{tabular}{|c|c|c|c|c|c|c|c|}
\hline & \multirow{2}{*}{$\begin{array}{l}\text { Live } \\
\text { births } \\
\text { No }\end{array}$} & \multicolumn{6}{|c|}{ First week deaths } \\
\hline & & $\begin{array}{l}\text { Obstetric } \\
\text { No }\end{array}$ & $\begin{array}{l}\text { Immaturity } \\
\text { No }\end{array}$ & $\begin{array}{l}\text { Malformation } \\
\text { No }\end{array}$ & $\begin{array}{l}\text { Infection } \\
\text { No }\end{array}$ & $\begin{array}{l}\text { Other } \\
\text { No }\end{array}$ & $\begin{array}{l}\text { Total } \\
\text { No }\end{array}$ \\
\hline $\begin{array}{l}1947-9 \\
1950-4 \\
1955-9 \\
1960-4 \\
1965-9 \\
1970-4 \\
1975-9 \\
\text { Totals }\end{array}$ & $\begin{array}{l}27716 \\
35530 \\
36680 \\
41394 \\
43011 \\
34224 \\
28398\end{array}$ & $\begin{array}{c}132(4 \cdot 8) \\
169(4 \cdot 8) \\
182(5 \cdot 0) \\
185(4 \cdot 5) \\
103(2 \cdot 4) \\
89(2 \cdot 6) \\
32(1 \cdot 1) \\
892\end{array}$ & $\begin{array}{l}240(8 \cdot 7) \\
253(7 \cdot 1) \\
240(6 \cdot 5) \\
245(5 \cdot 9) \\
252(5 \cdot 9) \\
171(5 \cdot 0) \\
102(3 \cdot 6) \\
1503\end{array}$ & $\begin{array}{c}54(1 \cdot 9) \\
67(1 \cdot 9) \\
68(1 \cdot 9) \\
92(2 \cdot 2) \\
83(1 \cdot 9) \\
97(2 \cdot 8) \\
66(2 \cdot 3) \\
527\end{array}$ & $\begin{array}{r}9(0.3) \\
13(0.4) \\
12(0.3) \\
6(0.1) \\
9(0.2) \\
7(0.2) \\
5(0.2) \\
61\end{array}$ & $\begin{array}{r}6(0 \cdot 2) \\
10(0 \cdot 3) \\
10(0 \cdot 3) \\
10(0 \cdot 2) \\
6(0 \cdot 1) \\
6(0 \cdot 2) \\
6(0 \cdot 2) \\
54\end{array}$ & \begin{tabular}{|r|}
441 \\
512 \\
512 \\
538 \\
453 \\
370 \\
211 \\
3037
\end{tabular} \\
\hline
\end{tabular}

Table 2 Sheffield. Number of live births and first week deaths from immaturity by place of birth

\begin{tabular}{|c|c|c|c|c|c|c|c|c|}
\hline & \multicolumn{2}{|c|}{ Hospital E } & \multicolumn{2}{|c|}{ Hospital $G$} & \multicolumn{2}{|c|}{ Hospital $H$} & \multicolumn{2}{|c|}{ Other places* } \\
\hline & Births & Deaths & Births & Deaths & Births & Deaths & Births & Deaths \\
\hline $\begin{array}{l}1947-9 \\
1950-4 \\
1955-9 \\
1960-4 \\
1965-9 \\
1970-4 \\
1975-9 \\
\text { Totals }\end{array}$ & $\begin{array}{r}2692 \\
4519 \\
5206 \\
7567 \\
9362 \\
13242 \\
9078\end{array}$ & $\begin{array}{r}10 \\
24 \\
15 \\
18 \\
39 \\
55 \\
22 \\
182\end{array}$ & $\begin{array}{r}5135 \\
7772 \\
8740 \\
10358 \\
12499 \\
11321 \\
9678\end{array}$ & $\begin{array}{r}116 \\
129 \\
131 \\
132 \\
130 \\
72 \\
56 \\
765\end{array}$ & $\begin{array}{l}1085 \\
6133 \\
6703 \\
8260 \\
9145 \\
8051 \\
8787\end{array}$ & $\begin{array}{r}18 \\
64 \\
78 \\
81 \\
80 \\
42 \\
20 \\
408\end{array}$ & $\begin{array}{r}16420 \\
17106 \\
16031 \\
15209 \\
12005 \\
1610 \\
855\end{array}$ & $\begin{array}{r}70 \\
37 \\
16 \\
14 \\
3 \\
2 \\
4 \\
146\end{array}$ \\
\hline
\end{tabular}

*Home and private nursing homes.

Table 3 Sheffield stillbirth and first day mortality rates, first week mortality rates from immaturity, and birthweight specific neonatal mortality rates for hospital $G(1953-79,<1500 \mathrm{~g}$ only) and the city

\begin{tabular}{|c|c|c|c|c|c|c|c|}
\hline & \multirow{2}{*}{$\begin{array}{l}\text { Still* } \\
\text { birth }\end{array}$} & \multirow{2}{*}{$\begin{array}{l}\text { First }+ \\
\text { day }\end{array}$} & \multirow{2}{*}{$\begin{array}{l}\text { First week } \dagger \\
\text { immaturity }\end{array}$} & \multicolumn{4}{|c|}{ Birthweight specific neonatal rate $\ddagger$} \\
\hline & & & & $<1500 \mathrm{~g}$ & $-2000 g$ & $-2500 g$ & Hosp $G<1500 \mathrm{~g}$ \\
\hline $\begin{array}{l}1947-9 \\
1950-4 \\
1955-9 \\
1960-4 \\
1965-9 \\
1970-4 \\
1975-9\end{array}$ & $\begin{array}{r}24.4 \\
22.6 \\
21.9 \\
16.8 \\
14.1 \\
11.9 \\
8.0\end{array}$ & $\begin{array}{r}8 \cdot 8 \\
10 \cdot 8 \\
11 \cdot 2 \\
9.5 \\
7 \cdot 5 \\
7.0 \\
6.9\end{array}$ & $\begin{array}{r}10 \cdot 1 \\
7 \cdot 1 \\
6 \cdot 5 \\
6 \cdot 6 \\
5 \cdot 8 \\
4 \cdot 8 \\
3 \cdot 6\end{array}$ & $\begin{array}{l}76 \cdot 1 \\
67 \cdot 2 \\
67 \cdot 5 \\
68 \cdot 6 \\
63 \cdot 9 \\
60 \cdot 5 \\
43.0\end{array}$ & $\begin{array}{l}19.2 \\
19.8 \\
18.8 \\
16.8 \\
15.2 \\
18.5 \\
10.9\end{array}$ & $\begin{array}{l}6 \cdot 1 \\
6 \cdot 1 \\
4 \cdot 6 \\
3 \cdot 5 \\
2 \cdot 6 \\
3 \cdot 6 \\
3 \cdot 4\end{array}$ & $\begin{array}{l}\overline{71} \cdot 3 \\
67 \cdot 9 \\
64 \cdot 2 \\
59 \cdot 3 \\
62 \cdot 1 \\
54 \cdot 2\end{array}$ \\
\hline
\end{tabular}

* Per thousand viable pregnancies.

†Per thousand live births.

$\ddagger$ Per hundred live births in each weight group, whole city, and hospital G. 
between the first 23 years and the past decade. $T$ values for each hospital were (linear model): E 1.53, G 1.37, H 2.06 and (exponential model): E 1.64, G 0.33 , H 3.25; significant $t$ values with 29 df are 2.04 at $p<0.05$ and 2.75 at $p<0.01$. The difference is clearly seen in table 2 and fig 2 .

\section{Discussion}

Stillbirths are increasingly being divided into "inevitable" and "preventable" for analysis and audit. Early neonatal deaths, however, are usually divided by birthweight rather than pathology, athough LBW deaths from malformations are of little relevance at present to neonatal audit. A decline in the proportion of infants dying from immaturity may be due to advances in intensive care but secular trends must be excluded first. A lengthy time span is required to identify any secular trend, thus increasing the difficulty of obtaining reliable data. To our knowledge, this is the first necropsy verified study of early neonatal mortality in a defined stable community that has been able to compare the outcome of different neonatal care facilities over a reasonable time interval.

The decline in proportions of infants dying from immaturity may be due to a decrease in the number of small babies born, to increasing health of immature babies, or to advances in medical and technical skills. This study has found that the decline in immaturity mortality occurred gradually in all three hospitals (fig 2 ), showing a clear secular trend. It is difficult to identify any intervention that could explain this gradual decline and it appears to be primarily of non-medical origin. Gordon has shown that the proportions of all births in Sheffield that are LBW have fallen, but offered no explanation except that this could not be attributed to neonatal intensive care. ${ }^{112}$ Even the accelerated decline in mortality in hospital $\mathrm{H}$ during the 1970 s began before advanced ventilatory and monitoring equipment were introduced but it shows a close temporal association with the reorganisation of the labour wards and neonatal units. This accelerated decline is also associated in time with increasing numbers of abortions, mostly in young or unmarried women who would be at increased risk of delivering prematurely had the pregnancy not been interrupted.

The increasing proportions of births in hospital must include many low risk pregnancies which will lower each hospital's immaturity rate, but this cannot explain why the citywide mortality rate fell (table 1 ). A high necropsy rate $^{3}$ and the few pathologists precludes interobserver variation and no diagnostic swings were identified (table 1). The stillbirth rate fell faster than the crude first day mortality rate (table 3) thus excluding a shift towards increased registration of stillbirths as the explanation for the fall in immaturity death rate. Increasing obstetric intervention, however, may be saving some babies from stillbirth only to die in the first few hours. There is no evidence that Sheffield SCBUs have merely postponed death until after the seventh day. ${ }^{13}$ The LBW mortality rate in hospital G (table 3) confirms that the observed trend in immaturity mortality is real. We therefore infer that a secular trend is occurring among Sheffield's pregnancies and that, in addition, medical efforts may accelerate this trend. Before attributing neonatal deaths to inadequate medical facilities, due attention must be paid to underlying trends.

The secular trend remains unexplained but social factors appear to be more important than medical ones. The decline in LBW births and in proportions of infants dying from immaturity suggests that a biological change may be occurring among Sheffield's mothers. Low levels of migration ${ }^{5}$ are against the possibility of healthier women simply moving into the city and altering the genetic pool. A biological change, however, could arise from greater health during the mother's own gestation and childhood. Baird found a steady increase in the height and weight of Aberdeen girls at school entry. ${ }^{14}$ Similar improvements among Sheffield's children could be showing in the health of their babies. If this is so there would be a generation delay before today's advances in child health become fully apparent in the community. This cannot be claimed for medical interventions after the age of childbearing. ${ }^{15}$ Increased investment in obstetric and paediatric services may be producing previously unappreciated improvements in the nation's health.

We are grateful to the Registrar General, the Sheffield Registrar of Births, Deaths and Marriages, the Sheffield Coroner, Sheffield Health Authority (Information Services), and Sheffield's pathologists for allowing access to their records. We are also grateful to the paediatricians, obstetricians, and pathologists in Sheffield and elsewhere who gave much time in discussion, especially Dr S L B Duncan, Dr R R Gordon, Professor R D G Milner, and Professor J L Emery.

This study was assisted by a grant from West Midlands Regional Health Authority (locally organised research).

\section{References}

${ }^{1}$ Office of Health Economics. Perinatal mortality in Britain-a question of class. London: OHE, 1979. (Office of Health Economics briefing No 10.) 
${ }^{2}$ House of Commons. Perinatal and neonatal mortality. Second report from the Social Services Committee. HMSO: London, 1980. (Short Committee.)

${ }^{3}$ Sunderland R, Sunderland EP. Invalid certification of young deaths. Arch Dis Child 1983; 58: 867-71.

4 David RJ, Siegel E. Decline in neonatal mortality, 1968 to 1977: better babies or better care? Pediatrics 1983; 11 $531-40$.

${ }^{5}$ Pollard S, Hunt AJ. The city of Sheffield. The growth of population. In: Linton DL, ed. Sheffield and its region. A scientific and historical survey. Sheffield: British Association for the Advancement of Science, 1956.

${ }^{6}$ Dowding VM. Distributions of birthweight in seven Dublin maternity units. Br Med J 1982; 284: 1901-4.

${ }^{7}$ Sunderland R, Emery JL. The mortality and birth rates of spina bifida during a period of treatment, selection and antenatal screening in Sheffield, 1963-1978. Z Kinderchir 1979: 28: 294-301.
${ }^{8}$ Dunn PM, Speidel BD, Hughes Davies TH. Conservative care of the newborn baby. Arch Dis Child 1979; 54: 482-4.

${ }^{9}$ Roberton NRC, Hughes Davies TH. Conservative care of the newborn baby. Arch Dis Child 1979; 54: 484-5.

${ }^{10}$ Reynolds O, Stewart A, Houlsby WT, et al. Comparison of neonatal management methods for very low birthweight babies. $\mathrm{Br} \mathrm{Med} J$ 1980; 281: 1488-90. (Various letters.)

${ }^{11}$ Gordon RR. Disproportion in the falling birth rate. $\mathrm{Br}$ $\overline{M e d} \bar{J}$ 1977; ii: 939-40.

${ }^{12}$ Gordon RR. Neonatal and "perinatal" mortality rates by birth weight. Br Med J 1977; ii: 1202-4.

${ }^{13}$ Sunderland $R$. Children's building bricks for three dimensional illustrations. Lancet 1980; ii: 863.

${ }^{14}$ Baird D. Epidemiological patterns over time. In: Reed DM, Stanley FJ, eds. The epidemiology of prematurity. Baltimore: Urban and Schwarzenberg, 1977.

${ }^{15}$ Mather HG, et al. Acute myocardial infarction, home or hospital treatment. $\mathrm{Br}$ Med J 1971; iii: 334-8. 